manchen Harnen vorkommende, mit Eisenchlorid sich röthende Substanz Acetessigsäure sei, hat durch R. v. Jaksch*) Bestätigung gefunden. Derselbe schüttelte frischen Harn, welcher die angeführte Reaction darbot, nach dem Ansäuern mit einem Zwanzigstel des Volums verdünnter Schwefelsäure $(1: 8)$, mit Aether aus nnd band die in Aether übergegangene Säure an eine Base, wodurch der sonst rasch eintretenden Zersetzung vorgebeugt wurde. $\mathrm{Zu}$ diesem Behufe schüttelte er den abgehobenen Aether mit Wasser, in welchem ein Metalloxyd (Kupferoxyd) oder ein Carbonat (von Baryum, Zink, Ammonium) suspendirt oder gelöst war. Die so erhaltenen wässerigen Lösungen acetessigsaurer Salze wurden im Vacuum möglichst rasch eingedunstet. Es blieb ein schmieriger Rückstand, der mit absolutem Alkohol aufgenommen und nach dem Filtriren wieder zur Trockne gebracht wurde. Das Verhalten der so gewonnenen Salze stimmte vollständig mit jenem überein, welches die von Ceresole**) aus Acetessigester dargestellten Salze der Acetessigsäure darbieten. Sie waren nicht krystallisirbar und schon in der Kälte der Zersetzung unterworfen; ihre wässerigen Lösungen wurden von Silbernitrat nicht gefällt; mit Eisenchlorid gaben sie die charakteristische violette, bei. Ueberschuss des Reagens bordeauxrothe Färbung, welche in der Kälte bei 24 stündigem Stehen, schneller auf Zusatz von Mineralsäuren, beim Sieden in wenigen Minuten verblasste. (Unterschied von Phenol, Salicylsäure, Ameisensäure, Essigsäure, Rhodanwasserstoff.) Beim Kochen der wässrigen Lösung für sich oder mit Säure lieferten sie die charakteristischen Zersetzungsproducte der Acetessigsäure: Aceton und Kohlensäure.

Neues Verfahren zur Bestimmung des Harnstoffs. L. Hugo un en $q^{* * *}$ ) filtrirt den Harn, in dem die Bestimmung vorgenommen werden soll, über Thierkohle, verdünnt mit Wasser und erhitzt in zugeschmolzenen Röhren auf $140^{\circ}$. Das aus dem Harnstoff entstandene kohlensaure Ammon wird alkalimetrisch unter Benutzung des als Orange No. 3 im Handel befindlichen Farbstoffs als Indicator bestimmt. In vier vergleichenden Versuchen, die $\dot{\mathrm{H}} \mathrm{u} \mathrm{g}$ o u $\mathrm{n}$ en $\mathrm{q}$ mittheilt, gab dieses Verfahren Zahlen, die, etwas höher als die mit Bromlange erhaltenen, doch noch beträchtlich hinter den nach Liebig ermittelten zurückblieben. Die

*) Zeitschrift f. physiol. Chemie 7, 487.

**) Ber. d. deutsch. chem. Gesellsch. z. Berlin 15, 1326 u. 1871.

***) Comptes rendus 97, 48. 
Methode ist nach Hugounenq auch bei Eiweissharnen - nach Ausfällung des Eiweisses - nicht aber bei zuckerhaltigem oder magnesiareichem Harn anwendbar.

Ein Verfahren zur Bestimmung der Harnsäure hat E. A. Cook*) angegeben. $300-400 c c$ Harn versetzt man mit einigen Tropfen starker Natronlauge und lässt den Phosphatniederschlag sich absetzen. $\mathrm{Zu} 100 \mathrm{cc}$ des Filtrats fügt man $4 c c$ einer Lösung von schwefelsaurem Zink (1:3) hinzu, versetzt mit Alkali; bis die Flitssigkeit nur noch schwach sauer reagirt, und filtrirt den erhaltenen Niederschlag, welcher die Harnsäure enthält, ab. Zum Auswaschen des Niederschlags dient eine gesättigte Lösung von harnsaurem Zink, welche durch Auflösen von etwas schwefelsaurem Zink in Wasser, Zusatz von harnsaurem Natron bis zur Bildung eines Niederschlags und Filtriren erhalten wird. Der ausgewaschene Niederschlag wird sodann sammt Filter in einem Azotometer mit $50 \mathrm{cc}$ Bromlauge zusammengebracht. Die allmählich eintretende Gasentwickelung ist in einer halben Stunde beendigt. Nach einem Versuche Cook's liefern $0,0648 g$ Harnsäure, als Natronsalz mit Zinksulfat in angegebener Weise gefällt, $8 \mathrm{cc}$ Stickstoffgas bei $760 \mathrm{~mm}$ Druck und $15^{1 / 2}{ }^{\circ} \mathrm{C}$. Die Anwesenheit von Ammonsalzen erweist sich bei genügendem Auswaschen nicht als störend. - Die Bedenken, welche die eben mitgetheilte Vorschrift Cook's erwecken muss; haben durch C. A r nold**) Ausdruck gefunden, welcher besonders darauf aufmerksam macht, dass es vorläufig unmöglich ist aus dem erhaltenen Stickstoffvolum die. Menge der Harnsäure zu berechnen, da die Zersetzung derselben durch Bromlauge je nach dem Gehalte der Lauge an Natron und an Brom wechselnde Gasmengen ergibt.

\section{Zum Nachweis und zur annähernden Bestimmung des Zuckers}

im Harn bedient sich G. Johnson ${ }^{* * *}$ ) des Verhaltens der Pikrinsäure beim Kochen mit alkalischer Zuckerlösung. Dabei erfolgende Bildung der dunkelroth gefärbten Pikraminsäure weist auf Gegenwart von Zucker hin; gleichzeitig kann die Intensität der Färbung als Maassstab für die Menge des vorhandenen Zuckers dienen. Als Vergleichsobject für eine solche colorimetrische Bestimmung benutzt Johnson bei der geringen Haltbarkeit von Pikraminsäurelösungen essigsaures Eisenoxyd. Doppel-

*) Brit. med. Journ. vom 5. April 1882.

**) Repertor. f. analyt. Chemie 3, 19.

***) Brit. med. Journal 1883, p. 504. 